\title{
Formiminoglutamic aciduria
}

INSERM

\section{Source}

INSERM. (1999). Orphanet: an online rare disease and orphan drug data base.

Formiminog/utamic aciduria. ORPHA:51208

A rare disorder of folate metabolism and transport characterized, biochemically, by elevated formiminog lutamate in urine and plasma due to glutamate

formiminotransferase deficiency, associated with a highly variable clinical phenotype, ranging from developmental delay, intellectual disability and anemia to normal development without anemia. Increased hydantoin-5-propionic acid and/or folate in plasma may also be associated. 